\title{
REVIEW
}

\section{The Genetic Contribution of the Natriuretic Peptide System to Cardiovascular Diseases}

\author{
TOMOHIRO NAKAYAMA
}

Division of Receptor Biology, Advanced Medical Research Center, Nihon University School of Medicine, Ooyaguchi-kamimachi, 30-1 Itabashi-ku, Tokyo 173-8610, Japan

\begin{abstract}
Three types of natriuretic peptides (NP) have been isolated: atrial natriuretic peptide (ANP), brain natriuretic peptide (BNP), and C-type natriuretic peptide (CNP). The NP family elicits a number of vascular, renal and endocrine effects that help to maintain blood pressure and extracellular fluid volume. These effects are mediated by the specific binding of NP to cell surface receptors that have been characterized, purified and cloned from cells of the vasculature, kidney, adrenal gland and brain. There are 3 subtypes of NP receptors: type A natriuretic peptide receptor (NPRA), type B natriuretic peptide receptor (NPRB), and type C natriuretic peptide receptor (NPRC). All 3 subtypes affect cellular second messenger activity. NPRA and NPRB are guanylyl cyclase receptors, and their activation increases cGMP levels. Activation of NPRC results in inhibition of adenylyl cyclase activity. Human NPRA has a high structural homology with human NPRB, and contains a highly-conserved guanylyl cyclase domain. ANP and BNP bind primarily to NPRA, which is found in the vasculature, causing vasodilation and inhibition of vascular smooth muscle cell proliferation. The present paper contains a review of NPs and their receptors and the genetic contribution of the NP system to cardiovascular diseases such as essential hypertension and myocardial infarction.
\end{abstract}

Key words: Natriuretic peptide, ANP, BNP, Natriuretic peptide receptor, Essential hypertension, Association, Susceptibility gene

(Endocrine Journal 52: 11-21, 2005)

AN atrial natriuretic peptide was isolated and purified by Japanese researchers in 1983-1984 [1]. Subsequently, a brain natriuretic peptide (BNP) was isolated [2]. Since then, methods of measuring plasma peptide levels have been developed, clinically applied, and become covered by health insurance. Plasma natriuretic peptide levels were found to vary (particularly, to increase) in various cardiovascular diseases, making their measurement very useful for diagnosis, treatment monitoring and prognosis prediction. No other substances have come into routine clinical use in the 10 short years following their discovery. This vividly demonstrates the clinical importance of natriuretic peptides. The whole picture of the natriuretic peptide system, including its receptors and second messengers,

Correspondence to: Tomohiro NAKAYAMA M.D., Division of Receptor Biology, Advanced Medical Research Center, Nihon University School of Medicine, 30-1 Ooyaguchi-kamimachi, Itabashi, Tokyo 173-8610, Japan is now being clarified, and relationships between it and osteoporosis and renal disease have been suggested. This paper outlines the natriuretic peptide system and related genes, and describes recent findings on the relationships between gene mutations and cardiovascular diseases, particularly essential hypertension.

\section{Overview of natriuretic peptides and their receptors}

In addition to having a blood-pumping action, the heart has been predicted to synthesize and secrete hormones as an endocrine organ. In the latter half of the 1950s, electron-microscopic observation demonstrated the presence of secretory granules in the atrial cells. In the latter half of the 1970s, de Bold et al. discovered that the number of these secretory granules changes under conditions of varying body fluid volume and blood pressure, and reported that the intravenous in- 
jection of atrial myocardial extract into rats caused a profound natriuresis and decrease in blood pressure [3], suggesting the existence of atrial natriuretic factor (ANF). Between the end of 1983 and 1984, de Bold et al. and Kangawa and Matsuo isolated a 28-aminoacid peptide hormone from human and rat atrial tissue, and named it atrial natriuretic peptide (ANP) [1]. This discovery showed that the heart itself is also a hormone-secreting (endocrine) organ, despite its being regarded solely as a blood-pumping organ. BNP (later found to be secreted mainly by the heart ventricle), which is structurally similar to ANP [2], was purified from the swine brain in 1988, and C-type brain natriuretic peptide (CNP) in 1990. Currently, the natriuretic family is known to consist of peptides derived from at least 3 different genes (Fig. 1).

Previously, 2 types of natriuretic peptide receptors had been assumed to exist: guanylate cyclase (GC)coupled receptors that appeared to be involved in the expression of the biological actions of natriuretic peptides, and receptors of which the mechanisms of intracellular signal transduction were unknown and that appeared to be involved in the clearance of natriuretic peptides. GC is an enzyme involved in the production of cyclic guanosine monophosphate (cGMP) from the substrate guanosine triphosphate (GTP). In 1988, Fuller et al. cloned the cDNA for the receptor that was considered to be involved in the clearance of natriuretic peptides, from cultured bovine smooth muscle cells [4]. This receptor is an approximately $60-\mathrm{kDa}$ homodimer of 496-amino-acid subunits, with an intracellular domain of only 37 amino acids, and is called the clear- ance receptor (NPRC) because of its involvement in the clearance of natriuretic peptides. The LDL and transferrin receptors are known to have a similar clearance action. On the other hand, in 1989, Garbers et al. showed that the receptor for the sea urchin motilityactivating factor resact was a membrane-type GC itself, and cloned a novel membrane-type GC using the intracellular domain of resact as a probe. When this membrane-type GC was expressed in mammalian cells, it was capable of binding to ${ }^{125} \mathrm{I}$-ANP and producing cGMP after ANP stimulation, suggesting that the receptor mediated the previously assumed main biological actions of ANP. Later, subtypes of this receptor were discovered from the rat brain and the human placenta; therefore, the first and second reported receptors are called A-type receptor (NPRA), or GC-A, and B-type receptor (NPRB), or GC-B, respectively.

\section{Genes for the natriuretic peptide system and peptide structure}

\section{Natriuretic peptides}

The genes for the 3 natriuretic peptides, ANP [5], BNP [6] and CNP [7] are located at different loci (Fig. 2 ). In humans, the ANP and BNP genes are tandemly located on chromosome $1 \mathrm{p} 36.2$, only $8 \mathrm{kbp}$ apart from each other, in the order of BNP and ANP from the $5^{\prime}$ side. The CNP gene is located between 2 q24 and the $2 q$ terminus. These 3 genes contain 3 exons each, and the relationship between the exons and introns is con-

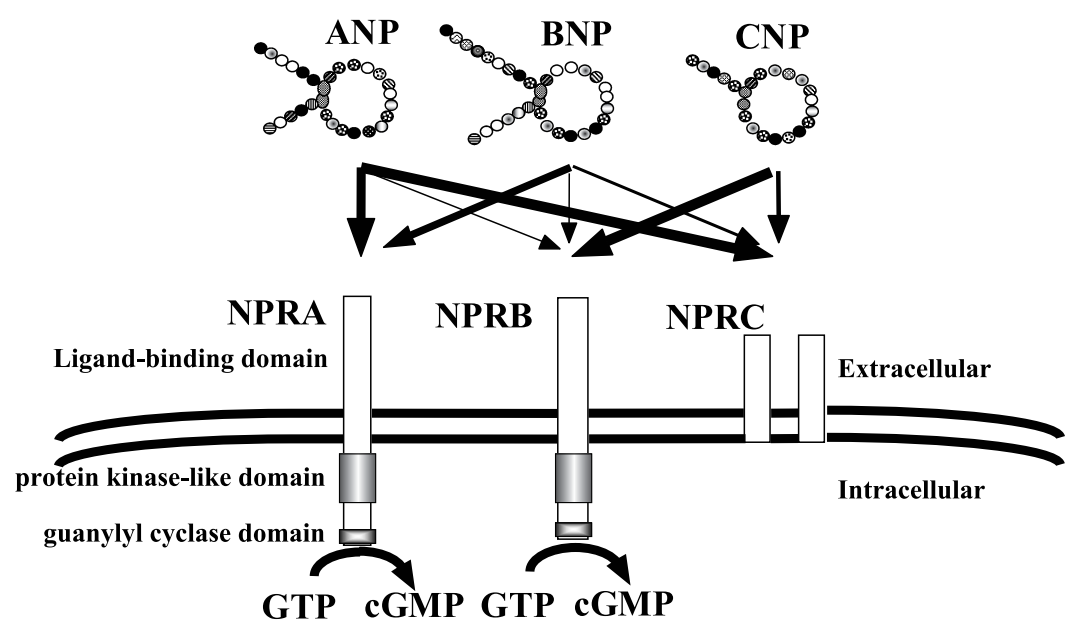

Fig. 1. NP system and ligand selectivity. 


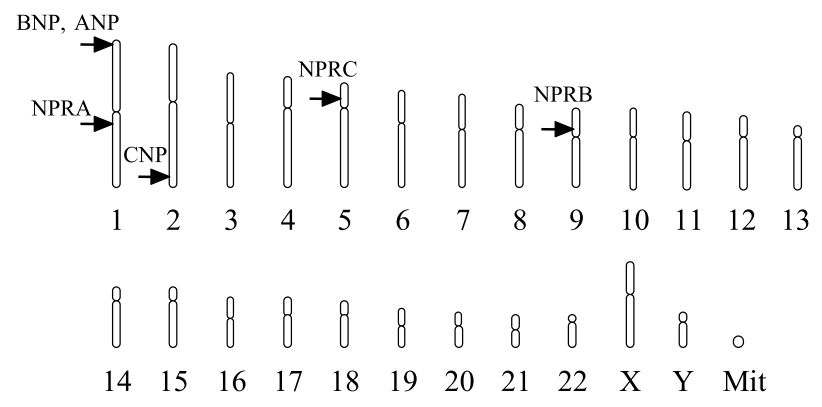

Fig. 2. Chromosome localization of genes encoding NP systems.

served. The natriuretic peptide family is considered to have arisen through gene duplication events during evolution. These genes are transcribed to mRNA, and then translated into the respective precursors. Subsequently, some N-terminal amino acids are cleaved off, and the mature peptides are formed and secreted from the cells. Mature human ANP, BNP and CNP are composed of 28,32 , and 22 amino acid residues, respectively, cyclized by means of a disulfide linkage. This cyclic moiety has an especially high amino acid sequence homology, consists of 17 amino acid residues, and is considered important for binding to receptors. Figure 1 shows the primary structure of human natriuretic peptides. The primary amino acid structure of ANP and CNP, particularly the latter, is conserved between different species; therefore, CNP is the ancestor gene, considered to have evolved into ANP and BNP. On the other hand, BNP characteristically varies relatively greatly among species. Several ATTTA sequence repeats involved in the destabilization of mRNA are present in the 3'-untranslated region of the BNP gene. This ATTTA sequence is frequently observed in oncogenes and early response genes.

\section{Natriuretic peptide receptors}

The 3 natriuretic peptide receptors genes are located at different loci (Fig. 2): NPRA [8] at 1q21-22, NPRB [9] at 9p21-p12, and NPRC at 5p14-p13. Our group elucidated the structure of all of these genes. The NPRA [10] and NPRB [11] genes are structurally very similar (Fig. 3). The entire NPRA and NPRB genes span approximately $16 \mathrm{kbp}$ each, and consist of $22 \mathrm{ex}-$ ons each. Exon 1 of the NPRA gene is $721 \mathrm{bp}$ long from the initiation codon, whereas that of the NPRB gene is the longest, at $667 \mathrm{bp}$ from the initiation codon. All other exons have similar lengths and codon inter- ruptions. Both genes are paralogous, and seem to have evolved from a common ancestor gene. The overall cDNA homology between NPRA and NPRB is $64 \%$, but the homology of the cDNA of the transmembrane and intracellular domains between them is high at $71 \%$, which is consistent with the similarity of their intracellular domains having GC activity.

The bovine NPRC gene has been reported to consist of 8 exons and to span approximately $70 \mathrm{kbp}$. Recently, we have shown that the human NPRC is structurally very similar to the bovine counterpart.

Using the thermal asymmetric interlaced-polymerase chain reaction (TAIL-PCR) [12] we first succeeded in cloning [10] and isolating the 5'-flanking regions of the NPRA [13] and NPRB [11] genes. This method, the details of which are omitted here, is epoch-making in that it allows cloning by PCR alone without library screening. Since both genes had no TATA box, they were considered housekeeping genes. We found the presence of an inverted CCAAT box upstream of NPRA, with scattered Sp1, AP2, and zeste ciselements, and 2 shear stress-responsive elements (SSRE). The NPRB gene from the initiation codon to approximately $780 \mathrm{bp}$ upstream was high in GC content, at $69 \%$, and was scattered with $7 \mathrm{Sp} 1$ sites and 15 AP2 sites. These cis-elements are considered to be involved in translation regulation.

NPRA and NPRB are single-transmembranedomain receptors with a very similar basic structure (Fig. 3). NPRA is an approximately $115-\mathrm{kDa}$ glycoprotein, and the extracellular, transmembrane and intracellular domains consist of 441, 21 and 568 amino acid residues, respectively. The intracellular domain contains a protein kinase-like domain homologous to protein kinases and a GC domain with enzyme activity. The homology between the protein kinase-like domains of NPRA and NPRB is $63 \%$, that between the GC domains is high at $88 \%$, and that between the extracellular domains, including the ligand-binding domain, is relatively low at $44 \%$. We speculate that these findings are related to differences in ligand selectivity, as described below. Activated GC increases intracellular cGMP levels, thereby exerting various biological activities. 


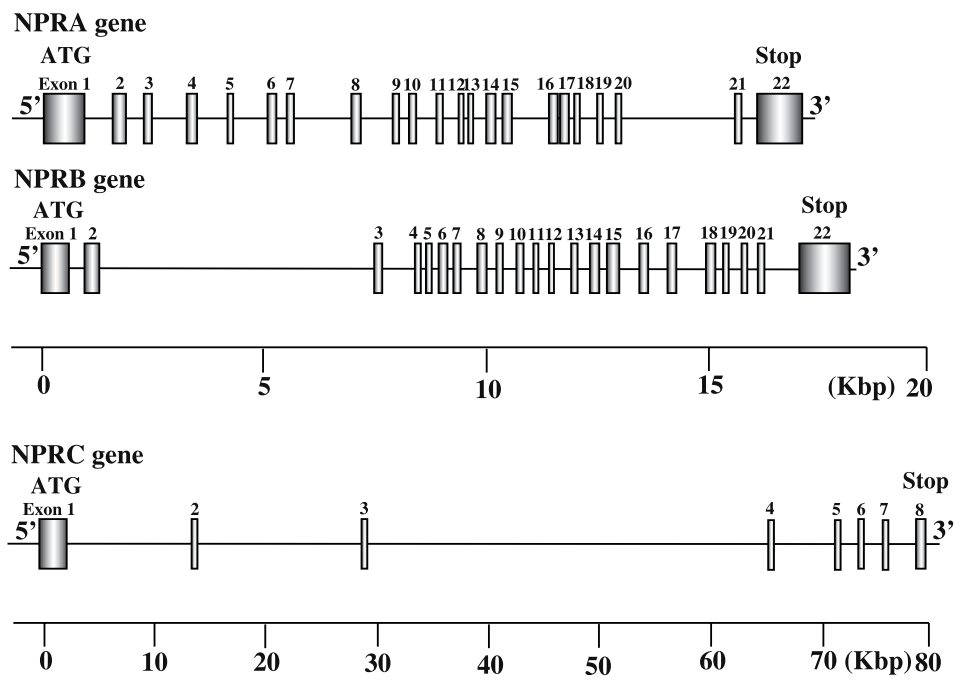

Fig. 3. Organization of the human NPRA gene, NPRB gene and NPRC gene.

\section{Secretion mechanism of the natriuretic peptide system}

Under normal conditions, ANP is mainly synthesized and secreted in the atria, and perfused to the coronary sinus. The amount of ANP synthesized in the ventricles is only approximately one-hundredth of that synthesized in the atria, and the total ANP content of the ventricles is approximately one-thirtieth of that of the atria. However, in the heart failure state, the synthesis and secretion of ANP in the ventricles markedly increases, reaching about the same level of biosynthesis as that in the atria [14]. The peptide synthesized in the atria is stored in the secretory granules, and secreted in response to stimuli via the regulated pathway. In contrast, the peptide synthesized in the ventricles is not stored, but directly secreted via the constitutive pathway. Thus, ANP secretion not only reflects increased or decreased synthesis in the atria and ventricles, but also is regulated by the release from the atrial secretory granules. ANP secretion is known to increase in response to increased atrial wall tension. However, in a pathological state, such as cardiac tamponade, in which increased intraatrial pressure is not accompanied by increased atrial volume, ANP secretion increases slightly, suggesting that atrial myocardial stretch itself is important. Stretch receptors on myocardial cells are considered to sense these stretch stimuli and transmit them into the cells, but the details are unknown. Pacing and tachycardia increase the frequency of depolarization and subsequent intracellular inflow of $\mathrm{Ca}^{2+}$, and promote the release from secretory granules, thereby increasing the secretion of ANP. An increased pressure or volume load due to increased ventricular preload or afterload stimulates ANP secretion. Since ANP secretion follows the constitutive pathway as described above, increased gene transcription is directly reflected in increased secretion.

In contrast to ANP, BNP is mainly synthesized and secreted in the ventricles of the normal heart, and the secretion from the ventricles markedly increases in the heart failure state [15]. Thus, the site of BNP synthesis in both the normal and heart failure states is the ventricles. Therefore, the secretion of BNP occurs only through the ventricular myocyte-specific constitutive pathway, and increased or decreased gene transcription is directly reflected in the amount of BNP secretion.

Unlike ANP mRNA, BNP mRNA transcribed from the BNP gene is characterized, as described above, by its fast turnover due to the presence of mRNA-destabilizing AUUUA repeats in the 3'-untranslated region, suggesting that the synthesis and secretion of BNP in the ventricles are closely controlled by mRNA levels according to changing amounts of load on the myocardium. Thus, the amount of BNP secretion is directly controlled by the amount of synthesis in the ventricles, that is, by fluctuations in gene transcription: in pathological states with increased ventricular preload and afterload, such as acute myocardial infarction and dilated cardiomyopathy, the expression of the BNP gene increases, resulting in an increase in the amount of 
BNP secretion.

CNP is expected to function also as a neuropeptide because of its additional presence in the brain and spinal cord, and is considered to function as a local factor in vascular endothelial cells and macrophages.

Northern blot analysis of the expression of receptor genes has shown that NPRA is abundantly expressed in the kidneys, lungs, and adrenal glands, but scantily expressed in the terminal ileum [8]; NPRB is abundantly expressed in the lungs, kidneys, adrenal glands, colon and brain [9]; and NPRC is abundantly expressed in the lungs and kidneys. Gene expression analysis in cultured cells has shown that NPRA is abundantly expressed in renal epithelial cells and vascular endothelial cells, and NPRB and NPRC are abundantly expressed in vascular smooth muscles and mesangial cells. A detailed study of vascular smooth muscles showed that, in vascular smooth muscles from the intact aortic tunica media, NPRA was abundantly expressed and NPRB scantily expressed, and little or no NPRC was expressed, but that, after passages of culture, little or no NPRA was expressed, and NPRB and NPRC were markedly increased in expression [16]. The splice variants of NPRB were reported, and some variants lack a guanylate cyclase activity [17] or serve as dominant negative forms [18].

\section{Ligand selectivity of natriuretic peptide receptors}

The magnitude of the biological activity of ANP, $\mathrm{BNP}$, and CNP depend greatly on their ligand selectivity (Fig. 1). Since the ligand for NPRA and NPRB is GC itself, their ligand selectivity can also be evaluated by their ability to produce cGMP [19]. In rat pheochromocytoma cells (PC12 cells) mainly expressing NPRA, rat ANP most potently stimulates cGMP production. Rat BNP also has a relatively high potency, whereas rat CNP virtually does not stimulate cGMP production [20]. Conversely, in human mesangial cells and rat smooth muscle cells, in which large amounts of NPRB are expressed, allogeneic CNP most potently stimulates cGMP production, but allogeneic ANP and BNP have a low ability to produce cGMP [21]. The binding affinity of human CNP for human NPRA receptors lacking the intracellular domain is 50 and 100 times as high as that of human ANP and BNP, respectively [22]. Thus, at least in humans and rats,
NPRA is a receptor with a high selectivity for ANP and BNP, and NPRB is a CNP-specific receptor. Furthermore, a study of the inhibitory effects of human and rat non-labeled ANP, BNP and CNP on the binding of ${ }^{125}$ I-ANP to allogeneic NPRC has reported that the binding affinity of ANP for NPRC was the highest, followed by that of CNP and that of BNP, which is only approximately one-tenth that of ANP [20]. These observations suggest that the NPRC-mediated clearance of BNP is lower than that of ANP, which is consistent with the finding that the blood half-life of intravenously injected BNP is about twice as long as that of intravenously injected ANP.

\section{Studies of the natriuretic peptide system in transgenic and knockout mice}

In transgenic mice made to overexpress ANP [23] or BNP [24] in the liver, the blood levels of ANP and BNP were 10- to 100-fold higher, the blood pressure was $20-25 \mathrm{mmHg}$ lower, and the heart was lighter than those in control mice. The ANP-overexpressing mice did not differ from the controls in cardiac output or heart rate, suggesting that the decrease in blood pressure was due to decreased peripheral vascular resistance. The ANP-overexpressing mice resembled the BNP-overexpressing mice in hemodynamic changes, which is consistent with NPRA being the receptor for both ANP and BNP. Conversely, knockout mice with reduced expression of endogenous ANP developed NaCl-sensitive hypertension: although knockout mice of different genotypes did not differ in blood pressure when they were fed a low $(0.5 \%) \mathrm{NaCl}$ diet, homozygous knockout mice with complete deletion of the ANP gene developed hypertension when they were fed a $2 \% \mathrm{NaCl}$ diet, and even heterozygous knockout mice had an elevated blood pressure when they were fed an $8 \% \mathrm{NaCl}$ diet [25]. In addition, homozygotes that were fed a $2 \% \mathrm{NaCl}$ diet showed a $40 \%$ increase in heart weight, compared with that of control wildtype mice.

Next, transgenic mice overexpressing the NPRA gene had significantly lower blood pressure than wildtype mice [26]. The observed NPRA gene-dose effect on blood pressure variation suggests that, in humans, differences in the expression of the NPRA gene and protein are also reflected in differences in blood pressure. Therefore, the gene-dose effect is also important 
in providing the rationale for the genetic analysis of the NPRA gene in essential hypertension. In NPRA heterozygous and homozygous knockout mice, the systolic blood pressure increased by about 10 and $30 \mathrm{mmHg}$, respectively [27]. The blood pressure increase was not influenced by a low $(0.008 \%)$ or high (8\%) $\mathrm{NaCl}$ diet, suggesting that it represents $\mathrm{NaCl}-$ insensitive hypertension, different from the hypertension in ANP knockout mice [25, 27]. The causes of this difference are unknown at present. A study has also reported that NPRA knockout mice have cardiac hypertrophy and experience sudden death [28]. NPRC heterozygous knockout mice did not show variation in blood pressure, whereas NPRC homozygous knockout mice showed a decrease in blood pressure of about $8 \mathrm{mmHg}$.

The results of these studies with mice mean not only that the genes for the natriuretic peptide system are closely involved in the mechanism of the development and progression of hypertension, but also that gene mutations influencing their transcription activities, receptor-binding abilities, and cGMP-producing abilities are sufficient to cause hypertension, and indicate the importance of genetic analysis of human natriuretic peptides and their receptors.

\section{Significance of the natriuretic peptide system in essential hypertension}

The measurement of plasma ANP and BNP levels for the diagnosis of heart failure and atrial fibrillation and the evaluation of therapeutic effects have been of practical use, and there is abundant literature on these subjects, to which we do not need to refer here. Instead, we will describe the significance of the natriuretic peptide system in essential hypertension. The causes of essential hypertension, which accounts for $80-90 \%$ of an estimated 20 million people with hypertension in Japan, remain unknown [29]. However, genetic factors are closely involved in essential hypertension, and recent genetic epidemiological studies have suggested that it is a polygenic disorder involving an estimated dozen or so genes. Since natriuretic peptides have a potent diuretic antihypertensive action, and the impaired action of the peptides may cause hypertension, their genes may be candidate genes for essential hypertension.

\section{Gene expression and blood levels of ANP and BNP in essential hypertension}

The onset of the hypotensive, diuretic and natriuretic action of ANP occurs rapidly after its administration to the body. Reflex tachycardia is rarely noted despite its hypotensive action, suggesting that it also has a sympatholytic action. Effects on other humoral factors include an inhibitory effect on the secretion of renin/ androsterone. From these observations, the importance of studies on the significance of the natriuretic peptide family in the etiology, pathogenesis, and treatment of hypertension has been emphasized from the beginning. As soon as a specific method of measuring ANP was developed, blood ANP levels were measured in clinical patients and animal models of hypertension. In human essential hypertension, blood ANP levels (although within normal limits in some patients) are considered to be slightly but significantly higher than those in normal controls. In experimental animals, blood ANP levels are known to be higher in models of genetic hypertension, that is, spontaneous hypertensive rats (SHR) and their variants, stroke-prone SHR (SHR-SP) and DOCA-salt hypertensive rats, than in control rats. The secretion of ANP is considered to be mainly stimulated by atrial myocardial stretch, and blood ANP levels increase especially in hypervolemic hypertension. In contrast, it has been demonstrated that BNP is mainly biosynthesized and secreted in the ventricles, and its blood levels sensitively reflect ventricular load or the pathological state of the ventricles [15]. Ventricular hypertrophy develops as a complication of essential hypertension in proportion to its severity, and increased blood BNP levels suggest the development of cardiac hypertrophy, especially concentric cardiac hypertrophy, making it worthwhile to measure blood BNP levels in essential hypertension.

\section{Genes for the natriuretic peptide system as candi- date genes for essential hypertension}

In recent years, molecular genetic techniques have been introduced in succession in etiological studies of polygenic diseases, in linkage studies, in sib-pair linkage studies of various candidate genes, and in related studies. Many genes or genetic loci associated with essential hypertension have been reported to date. Among them, chromosome 1p36 containing the ANP and BNP genes, chromosome 1q42-q43 containing the 
angiotensinogen gene, and chromosome 8p22 containing the lipoprotein lipase gene are considered important loci [17]. Studies of the natriuretic peptide receptor genes have reported the involvement of the NPRA gene in hypertension in Dahl salt-sensitive rats [30]. Indeed, individual patients with essential hypertension respond differently to the dosage of ANP in terms of hypotensive action and the reaction of the second messenger cGMP, suggesting that abnormalities in NPRA and NPRB contribute to the development of essential hypertension.

\section{Mutations in the natriuretic peptide system}

\section{Natriuretic peptides}

Many ANP polymorphisms were found by restriction fragment length polymorphism (RFLP) analysis in the 1980s before PCR came into widespread use. However, among these, the polymorphism with a C-to$\mathrm{G}$ substitution at position 664 in the 5'-untranslated region, the G191A polymorphism in exon 1, the deletion/insertion polymorphism and C1364A polymorphism (Hpa II polymorphism) in exon 2, and the T1766C polymorphism (Sca I polymorphism) in exon 3 have been identified to date. Linkages between the G191A and C1364A polymorphic loci and between the deletion/insertion and $\mathrm{T} 1766 \mathrm{C}$ polymorphic loci have been noted. C1364A polymorphism (Hpa II polymorphism) analysis showed that allele A is significantly more frequent in African Americans, but other studies reported that allele A could not be a marker of salt sensitivity in young normotensive individuals, and is not associated with salt sensitivity in the Chinese. In the polymorphism with a C-to-G substitution at posi- tion 664 in the 5 '-untranslated region, the $\mathrm{C} / \mathrm{C}$ genotype was significantly more frequent in the essential hypertensive group, but blood ANP levels did not differ according to genotypes, suggesting that the $\mathrm{C} / \mathrm{C}$ genotype is unlikely to be related to the pathological state [31]. In an association study between cerebral infarction (CI) and non CI, Rubattu et al. reported the ANP gene polymorphism was associated with risk of CI $[32,33]$, while there is a report showing an opposite result [34]. To the best of our knowledge there have been no association studies of cardiovascular diseases using polymorphisms or mutations in the BNP to date. An SNP (G2628A) in the 3'-untranslated region of the CNP gene has been reported to be associated with essential hypertension [35].

\section{Natriuretic peptide receptors}

After elucidating the structure of the natriuretic peptide receptor genes, we analyzed them for mutations or polymorphisms. We discovered an 8-bp deletion at the transcription factor AP2 site in the untranslated region of exon 1 by analyzing the 5'-flanking region of the NPRA gene (Fig. 4), and we had this published in Circulation Research [36]. We found this deletion in 8 of 200 essential hypertensive individuals and in 1 of 200 normotensive individuals $(\mathrm{p}=0.037)$. All affected individuals were heterozygous for the deletion, and the deletion patients with essential hypertension had significantly higher blood BNP levels than their nondeletion counterparts (Fig. 5). Compared with the non-deletion patients, the deletion patients had higher BNP levels for the mean blood pressure (Fig. 5). The luciferase assay of cells showed that the transcription activity was approximately $30 \%$ lower in the deletion type than in the non-deletion type, and a gel-shift assay

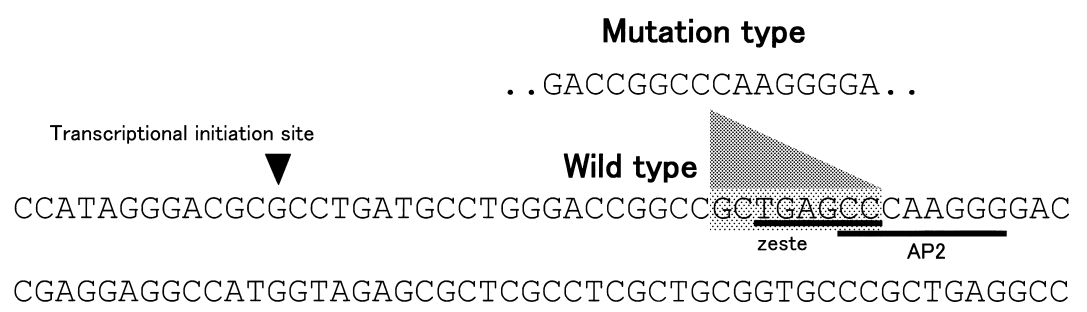

\section{ATG}

Fig. 4. Nucleotide sequence 5'-upstream of the human NPRA gene. ATG in bold type indicates the start codon, and the first nucleotide upstream of the ATG start codon is numbered -1. Cis-elements are underlined. The eight nucleotides missing in the deletion-type allele are indicated by dots. The transcription initiation site is shown by a black triangle. 

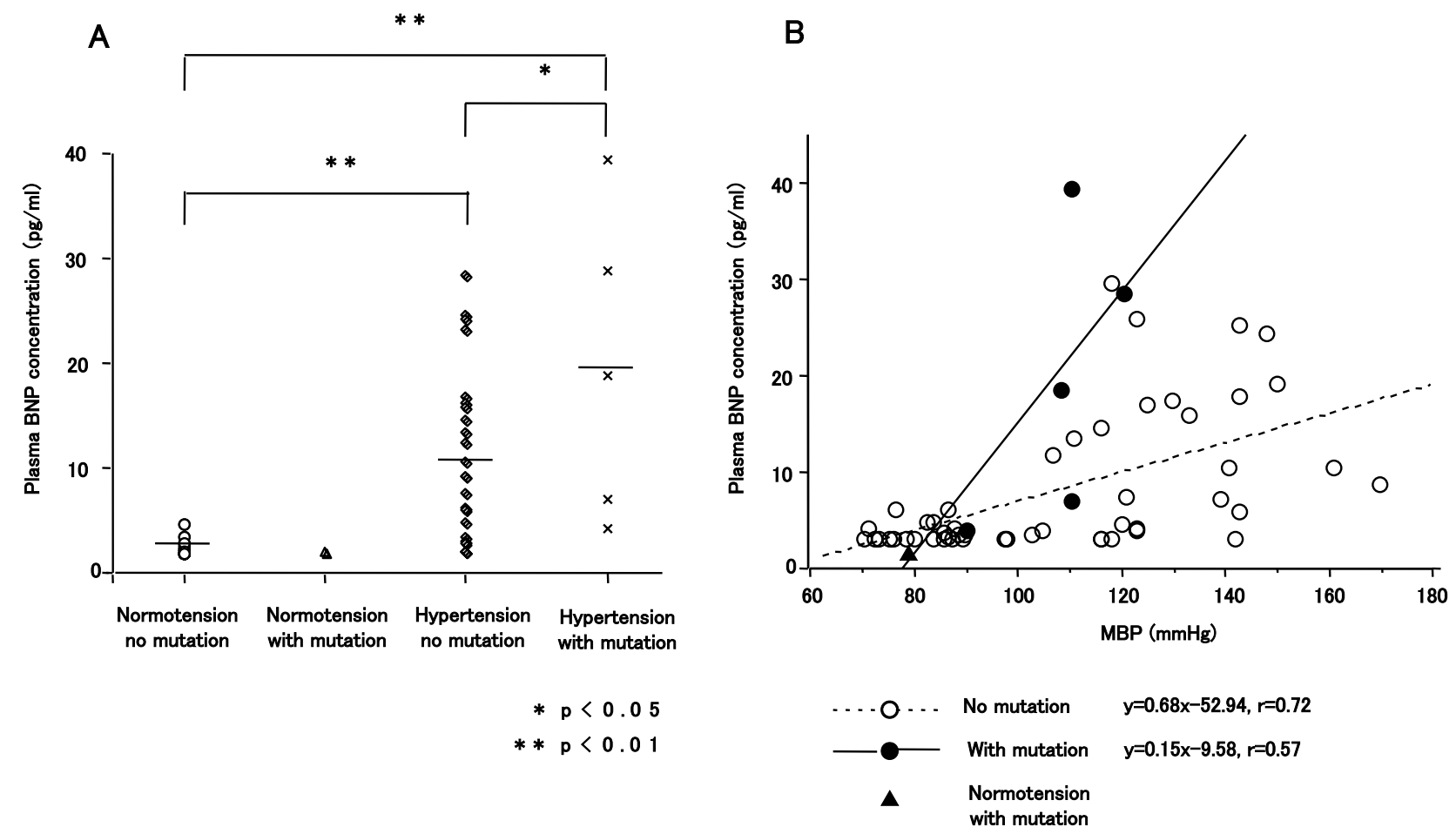

Fig. 5. A: Comparison of plasma BNP levels in each group. Plasma BNP levels in normotensive subjects without and with the deleted allele and in essential hypertensive patients without and with the deleted allele. B: Scatterplots show the relationships between plasma BNP levels, and mean blood pressure in subjects with the deleted allele and without the deleted allele. The slope of the plasma BNP levels in subjects with the deleted allele was steeper than that of subjects without the deleted allele.

demonstrated that AP2 did not bind to the deletion type. These findings indicate that the deletion in the untranslated region results in decreased transcription activity, leading to essential hypertension. The higher plasma BNP levels in the deletion patients with essential hypertension may have been compensatory for the functional impairment of NPRA. Very interestingly, 1 normotensive individual had left ventricular hypertrophy, which is consistent with a report that NPRA gene knockout mice have hypertension with left ventricular hypertrophy. Recently, it was reported that none of the 498 New Zealand patients with postmyocardial infarction carried the deletion allele. These findings suggest that this functional deletion polymorphism is rare outside Japanese populations [37].

Furthermore, we identified a novel missense mutation, M341I, consisting of a methionine (ATG) to isoleucine (ATC) substitution at nucleotide 1023 in exon 3 of the NPRA. Computer-aided three-dimensional structural analysis suggested that M341 exists in the loop between two $\alpha$-helices, and that the mutation may influence receptor activities by altering the conformation of the $\alpha$-helices (Fig. 6). We performed an

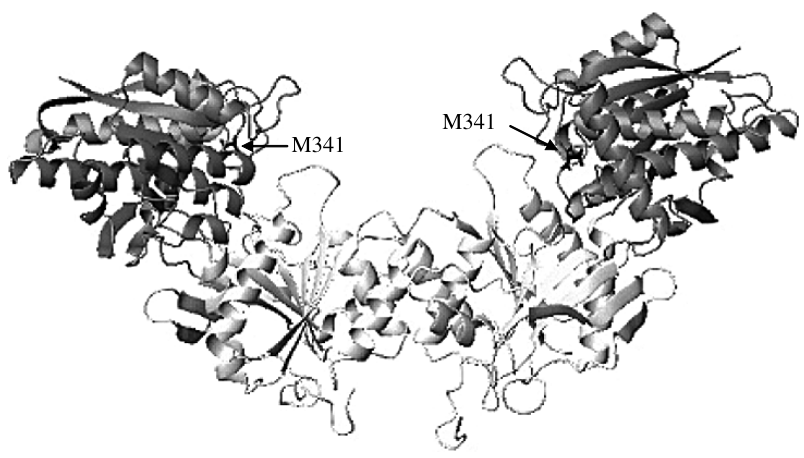

Fig. 6. Crystal structure of the NPRA hormone-binding domain dimer. Ribbon diagram showing the position of M341I as red. The direction of the crystal structure is as described previously [47].

association study of the mutation in 210 essential hypertensive patients and 210 healthy controls. The overall distribution of alleles was not significantly different between the control and essential hypertensive groups. However, the $\mathrm{C} / \mathrm{C}$ homozygous genotype was found only in the essential hypertensive group. The ratio of plasma brain natriuretic peptide (BNP)/mean blood pressure of the $\mathrm{C} / \mathrm{C}$ genotype was significantly 


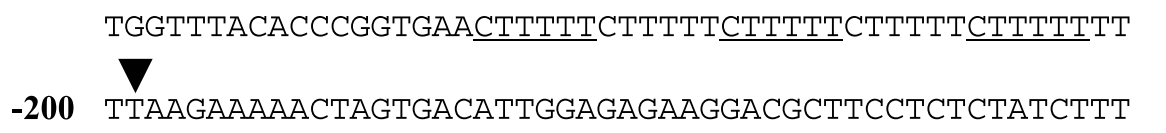

TGGCGCATTAGTGAAGgGgGTATTCTATTTTGTTAAAGCGCCCAAGGGGA

-100 CCGGGAACCTTGGAGAGAAGAGTGGGGAGGAAAGAGGAAGGGTGGGTGGG

GGGCAGAGGGCGAGTCGGCGGCGGCGAGGGCAAGCTCTTCTTGCGGCACG

ATG

Fig. 7. Nucleotide sequence of the $5^{\prime}$ nontranslated region of the NPRC gene. ATG in a box indicates the start codon, and the first nucleotide upstream of the ATG start codon is designated -1 . The variable number of tandem repeat (VNTR) consists of the 6 underlined nucleotides (CTTTTT). This figure shows the 5 repeat types. The major transcriptional initiation site is indicated by the triangle.

higher than that of the $\mathrm{G} / \mathrm{G}$ genotype or the $\mathrm{G} / \mathrm{C}$ genotype. We concluded that the significance of the homozygous M341I mutation in exon 3 is worth investigating for its possible association with essential hypertension [38]. The M341I missense mutation was reported to be associated with risk for myocardial infarction and may be a genetic marker of myocardial infarction in Japanese people [39].

Next, we discovered new variants in the NPRB gene: a GT repeat polymorphism in intron 2 , a $\mathrm{C}$ to $\mathrm{T}$ transition at nucleotide (nt) 2077 in exon 11 and a 9-bp insertion/deletion (I/D) in intron 18. The 11-repeat allele of the GT repeat polymorphism was significantly higher in the essential hypertensive group than in the normotensives [11]. C2077T polymorphism was not associated with myocardial infarction [40], and had complete linkage to the GT repeat polymorphism [41]. The I/D polymorphism was not associated with essential hypertension [42].

Before we screened possible variants in the NPRC, the organization of this gene was determined [43]. An A-to-C substitution polymorphism at position 55 upstream has been found, and individuals with the $\mathrm{C} / \mathrm{C}$ genotype have been reported to have significantly lower ANP levels and higher systolic blood pressure [44]. Recently we discovered a six-nucleotide repeat polymorphism located 4 base pairs (bp) upstream of the major transcriptional initiation site of the NPRC (Fig. 7). Although no significant difference in the overall frequency of this variable number of tandem repeat
(VNTR) was found between the normotension and essential hypertension groups, the blood pressure level of the essential hypertensive patients with the 5/6 genotype was significantly higher in obese subjects. This suggests that the VNTR of the 5'-flanking region of the NPRC gene influences blood pressure levels in obesity-associated hypertension [45]. Unanalyzed regions should be targeted for future molecular studies.

A combined analysis using variants in the NPRA and NPRC reported that allelic variants were associated with a family history of hypertension [46].

\section{Conclusion}

The above-described gene abnormalities of the natriuretic peptide system, including the abovedescribed NPRA gene mutations, may be established as a disease concept independent of the syndrome of essential hypertension of currently unknown origin. It is hoped that the genetic diagnosis of hypertension and its treatment tailored to individual pathological states will be performed in the future.

\section{Acknowledgement}

The author would like to thank Drs. Masayoshi Soma, Constantinos C Deltas, and Barry R Palmer for their helpful comments. 


\section{References}

1. Kangawa K, Matsuo H (1984) Purification and complete amino acid sequence of alpha-human atrial natriuretic polypeptide (alpha-hANP). Biochem Biophys Res Commun 118: 131-139.

2. Sudoh T, Kangawa K, Minamino N, Matsuo H (1988) A new natriuretic peptide in porcine brain. Nature 332: 78-81.

3. de Bold AJ, Borenstein HB, Veress AT, Sonnenberg H (1981) A rapid and potent natriuretic response to intravenous injection of atrial myocardial extract in rats. Life Sci 28: 89-94.

4. Fuller F, Porter JG, Arfsten AE, Miller J, Schilling JW, Scarborough RM, Lewicki JA, Schenk DB (1988) Atrial natriuretic peptide clearance receptor. Complete sequence and functional expression of cDNA clones. $J$ Biol Chem 263: 9395-401.

5. Nemer $\mathrm{M}$, Chamberland $\mathrm{M}$, Sirois $\mathrm{D}$, Argentin $\mathrm{S}$, Drouin J, Dixon RA, Zivin RA, Condra JH (1984) Gene structure of human cardiac hormone precursor, pronatriodilatin. Nature 312: 654-656.

6. Seilhamer JJ, Arfsten A, Miller JA, Lundquist P, Scarborough RM, Lewicki JA, Porter JG (1989) Human and canine gene homologs of porcine brain natriuretic peptide. Biochem Biophys Res Commun 165: 650-658.

7. Ogawa Y, Itoh H, Yoshitake Y, Inoue M, Yoshimasa T, Serikawa T, Nakao K (1994) Molecular cloning and chromosomal assignment of the mouse C-type natriuretic peptide (CNP) gene (Nppc): comparison with the human CNP gene (NPPC). Genomics 24: 383-387.

8. Lowe DG, Chang MS, Hellmiss R, Chen E, Singh S, Garbers DL, Goeddel DV (1989) Human atrial natriuretic peptide receptor defines a new paradigm for second messenger signal transduction. Embo $J$ 8: 13771384.

9. Chang MS, Lowe DG, Lewis M, Hellmiss R, Chen E, Goeddel DV (1989) Differential activation by atrial and brain natriuretic peptides of two different receptor guanylate cyclases. Nature 341: 68-72.

10. Takahashi $\mathrm{Y}$, Nakayama $\mathrm{T}$, Soma M, Izumi $\mathrm{Y}$, Kanmatsuse K (1998) Organization of the human natriuretic receptor A gene. Biochem Biophys Res Commun 246: 736-739.

11. Rehemudula D, Nakayama T, Soma M, Takahashi Y, Uwabo J, Sato M, Izumi Y, Kanmatsuse K, Ozawa Y (1999) Structure of the type B human natriuretic peptide gene and association of a novel microsatellite polymorphism with essential hypertension. Circ Res 83: 605-610.

12. Nakayama $T$, Soma M, Rahmutula D, Ozawa $Y$, Kanmatsuse K (2001) Isolation of the 5'-flanking region of genes by thermal asymmetric interlaced polymerase chain reaction. Med Sci Monit 7: 345-349.

13. Nakayama T, Soma M, Takahashi Y, Rehemudula D, Sato M, Uwabo J, Izumi Y, Kanmatsuse K (1999)
Nucleotide sequence of the 5'-flanking region of the type A human natriuretic peptide receptor gene and association analysis using a novel microsatellite in essential hypertension. Am J Hypertens 12: 1144-1148.

14. Saito Y, Nakao K, Arai H, Nishimura K, Okumura K, Obata K, Takemura G, Fujiwara H, Sugawara A, Yamada T (1989) Augmented expression of atrial natriuretic polypeptide gene in ventricle of human failing heart. J Clin Invest 83: 298-305.

15. Mukoyama M, Nakao K, Hosoda K, Suga S, Saito Y, Ogawa Y, Shirakami G, Jougasaki M, Obata K, Yasue H (1991) Brain natriuretic peptide as a novel cardiac hormone in humans. Evidence for an exquisite dual natriuretic peptide system, atrial natriuretic peptide and brain natriuretic peptide. J Clin Invest 87: 1402-1412.

16. Suga S, Nakao K, Kishimoto I, Hosoda K, Mukoyama M, Arai H, Shirakami G, Ogawa Y, Komatsu Y, Nakagawa O (1992) Phenotype-related alteration in expression of natriuretic peptide receptors in aortic smooth muscle cells. Circ Res 71: 34-39.

17. Hirsch JR, Skutta N, Schlatter E (2003) Signaling and distribution of NPR-Bi, the human splice form of the natriuretic peptide receptor type B. Am J Physiol Renal Physiol 285: F370-F374.

18. Tamura N, Garbers DL (2003) Regulation of the guanylyl cyclase-B receptor by alternative splicing. $J$ Biol Chem 278: 48880-48889.

19. Tamura N, Chrisman TD, Garbers DL (2001) The regulation and physiological roles of the guanylyl cyclase receptors. Endocr J 48: 611-634.

20. Kishimoto I, Garbers DL (1997) Physiological regulation of blood pressure and kidney function by guanylyl cyclase isoforms. Curr Opin Nephrol Hypertens 6: 5863.

21. Suga S, Nakao K, Hosoda K, Mukoyama M, Ogawa Y, Shirakami G, Arai H, Saito Y, Kambayashi Y, Inouye K (1992) Receptor selectivity of natriuretic peptide family, atrial natriuretic peptide, brain natriuretic peptide, and C-type natriuretic peptide. Endocrinology 130: 229-239.

22. Koller KJ, Lowe DG, Bennett GL, Minamino N, Kangawa K, Matsuo H, Goeddel DV (1991) Selective activation of the B natriuretic peptide receptor by Ctype natriuretic peptide (CNP). Science 252: 120-123.

23. Steinhelper ME, Cochrane KL, Field LJ (1990) Hypotension in transgenic mice expressing atrial natriuretic factor fusion genes. Hypertension 16: 301-307.

24. Ogawa $\mathrm{Y}$, Itoh H, Tamura N, Suga S, Yoshimasa T, Uehira M, Matsuda S, Shiono S, Nishimoto H, Nakao K (1994) Molecular cloning of the complementary DNA and gene that encode mouse brain natriuretic peptide and generation of transgenic mice that overexpress the brain natriuretic peptide gene. J Clin Invest 93: 1911-1921.

25. John SW, Krege JH, Oliver PM, Hagaman JR, Hodgin 
JB, Pang SC, Flynn TG, Smithies O (1995) Genetic decreases in atrial natriuretic peptide and salt-sensitive hypertension. Science 267: 679-681.

26. Oliver PM, John SW, Purdy KE, Kim R, Maeda N, Goy MF, Smithies O (1998) Natriuretic peptide receptor 1 expression influences blood pressures of mice in a dose-dependent manner. Proc Natl Acad Sci USA 95: 2547-2551.

27. Lopez MJ, Wong SK, Kishimoto I, Dubois S, Mach V, Friesen J, Garbers DL, Beuve A (1995) Salt-resistant hypertension in mice lacking the guanylyl cyclase-A receptor for atrial natriuretic peptide. Nature 378: 6568.

28. Oliver PM, Fox JE, Kim R, Rockman HA, Kim HS, Reddick RL, Pandey KN, Milgram SL, Smithies O, Maeda N (1997) Hypertension, cardiac hypertrophy, and sudden death in mice lacking natriuretic peptide receptor A. Proc Natl Acad Sci USA 94: 14730-14735.

29. Krozowski Z, Chai Z (2003) The role of 11 betahydroxysteroid dehydrogenases in the cardiovascular system. Endocr J 50: 485-489.

30. Deng Y, Rapp JP (1992) Cosegregation of blood pressure with angiotensin converting enzyme and atrial natriuretic peptide receptor genes using Dahl salt-sensitive rats. Nat Genet 1: 267-272.

31. Kato N, Sugiyama T, Morita H, Nabika T, Kurihara H, Yamori Y, Yazaki Y (2000) Genetic analysis of the atrial natriuretic peptide gene in essential hypertension. Clin Sci (Colch) 98: 251-258.

32. Rubattu S, Ridker P, Stampfer MJ, Volpe M, Hennekens CH, Lindpaintner K (1999) The gene encoding atrial natriuretic peptide and the risk of human stroke. Circulation 100: 1722-1726.

33. Rubattu S, Stanzione R, Di Angelantonio E, Zanda B, Evangelista A, Tarasi D, Gigante B, Pirisi A, Brunetti E, Volpe M (2004) Atrial natriuretic peptide gene polymorphisms and risk of ischemic stroke in humans. Stroke 35: 814-818.

34. Kato N, Ikeda K, Nabika T, Morita H, Sugiyama T, Gotoda T, Kurihara H, Kobayashi S, Yazaki Y, Yamori Y (2002) Evaluation of the atrial natriuretic peptide gene in stroke. Atherosclerosis 163: 279-286.

35. Ono K, Mannami T, Baba S, Tomoike H, Suga S, Iwai $\mathrm{N}$ (2002) A single-nucleotide polymorphism in C-type natriuretic peptide gene may be associated with hypertension. Hypertens Res 25: 727-730.

36. Nakayama T, Soma M, Takahashi Y, Rehemudula D, Kanmatsuse K, Furuya K (2000) Functional deletion mutation of the 5'-flanking region of the type A human natriuretic peptide receptor gene and its association with essential hypertension and left ventricular hypertrophy in the Japanese. Circ Res 86: 841-845.

37. Palmer BR, Frampton CM, Richards AM, Cameron VA, Nakayama T (2004) Absence of a NPR-A gene functional deletion allele in a postmyocardial infarction cohort from New Zealand. Circ Res 94: e86.
38. Nakayama T, Soma M, Mizutani Y, Xu X, Honye J, Kaneko Y, Rahmutula D, Aoi N, Kosuge K, Saito S, Ozawa Y, Kanmatsuse K, Kokubun S (2002) A novel missense mutation of exon 3 in the type A human natriuretic peptide receptor gene: possible association with essential hypertension. Hypertens Res 25: 395-401.

39. Nakayama T, Soma M, Saito S, Honye J, Sato M, Aoi N, Kosuge K, Haketa A, Kanmatsuse K, Kokubun S (2003) Missense mutation of exon 3 in the type A human natriuretic peptide receptor gene is associated with myocardial infarction. Med Sci Monit 9: CR505-510.

40. Rahmutula D, Nakayama T, Soma M, Takahashi Y, Uwabo J, Sato M, Izumi Y, Saito S, Honye J, Kanmatsuse K, Ozawa Y (2000) A C2077T polymorphism of the type $\mathrm{B}$ human natriuretic peptide receptor gene is not associated with myocardial infarction. Med Sci Monit 6: 1056-1060.

41. Rahmutula D, Nakayama T, Soma M, Takahashi Y, Uwabo J, Sato M, Izumi Y, Kanmatsuse K, Ozawa Y (2000) An insertion/deletion polymorphism in intron 18 of the type B human natriuretic peptide receptor gene is not associated with cerebral infarction. Hypertens Res 23: 173-176.

42. Rahmutula D, Nakayama T, Soma M, Sato M, Izumi Y, Kanmatsuse K, Ozawa Y (2001) Systematic screening of type $\mathrm{B}$ human natriuretic peptide receptor gene polymorphisms and association with essential hypertension. J Hum Hypertens 15: 471-474.

43. Rahmutula D, Nakayama T, Soma M, Kosuge K, Aoi N, Izumi Y, Kanmatsuse K, Ozawa Y (2002) Structure and polymorphisms of the human natriuretic peptide receptor C gene. Endocrine 17: 85-90.

44. Sarzani R, Dessi-Fulgheri P, Salvi F, Serenelli M, Spagnolo D, Cola G, Pupita M, Giantomassi L, Rappelli A (1999) A novel promoter variant of the natriuretic peptide clearance receptor gene is associated with lower atrial natriuretic peptide and higher blood pressure in obese hypertensives. J Hypertens 17: 13011305.

45. Aoi N, Soma M, Nakayama T, Rahmutula D, Kosuge K, Izumi Y, Matsumoto K (2004) Variable number of tandem repeat of the 5'-flanking region of type-C human natriuretic peptide receptor gene influences blood pressure levels in obesity-associated hypertension. Hypertens Res: in press.

46. Pitzalis MV, Sarzani R, Dessi-Fulgheri P, Iacoviello M, Forleo C, Lucarelli K, Pietrucci F, Salvi F, Sorrentino S, Romito R, Guida P, Rappelli A, Rizzon P (2003) Allelic variants of natriuretic peptide receptor genes are associated with family history of hypertension and cardiovascular phenotype. J Hypertens 21: 1491-1496.

47. van den Akker F, Zhang X, Miyagi M, Huo X, Misono KS, Yee VC (2000) Structure of the dimerized hormone-binding domain of a guanylyl-cyclase-coupled receptor. Nature 406: 101-104. 